\title{
Shale Oil and Gas Well Logging Evaluation in Liaohe Depression
}

\author{
Kang Chen ${ }^{1, a}$, Jinchuan Zhang ${ }^{1, b}$ and Xuan Tang ${ }^{1, c}$, \\ ${ }^{1}$ China University of Geosciences, Beijing, China, 100083 \\ a332644734@qq.com, ${ }^{\text {bzhangjc@cugb.edu.cn, }{ }^{c} 112722331 @ q q . c o m}$
}

\begin{abstract}
Keywords: Shale Oil and Gas, Well Logging Evaluation, Liaohe Depression, TOC
Abstract. Liaohe depression Paleogene shale has great potential in shale oil and gas exploration. Well logging technology is an effective means to evaluate shale oil and gas. The logging response characteristics of Paleogene shale were studied and the separation form of acoustictime and resistivity curves were classified. Thus, high quality shale was qualitatively and semi-quantitatively identified by types of curves separation form. Meanwhile, sedimentary environment of the formation of high quality shale was analyzed. By multivariate linear regression method, $\Delta \operatorname{lgR}$ technology was improved to calculate TOC(total organic carbon). The error of the calculated TOC is small, which indicate the improved formula has certain practicality in Liaohe depression.
\end{abstract}

\section{Introduction}

Shale gas is typical self-generated unconventional reservoirs which is stored in organic-rich dark mud and shale and its sandy or silty mudstone interlayer as free and adsorption state [1]. In recent years, shale oil and gas exploration and research is rising in China. The logging method for shale gas qualitative identification and quantitative evaluation are important technologies of shale gas exploration. Predecessors have done a lot of research in hydrocarbon source rocks well logging evaluation, oil and gas shale logging evaluation can be understood as the organic-riched source rocks well logging evaluation [2,3]. In this paper, based on the research of the liaohe depression logging data, the logging response characteristics and the identification law of shale oil and gas were discussed, and an effective logging evaluation of quality shale was carried out.

\section{Shale Gas Logging Response Characteristics}

Because of the richness of organic matter, shale oil and gas reservoir logging response characteristics are obviously different with conventional reservoir. Typically, kerogen formed in the reducing environment can precipitate uranium down, which has the characteristics of high natural gamma radiation. The density of kerogen is low, and the existence of kerogen greatly reduces the reservoir volume density. Kerogen also has high hydrogen index and lower photoelectric absorption index, which lead to the reservoir with high neutron porosity and low photoelectric capture cross section features. Hydrocarbon saturation is a little high in shale oil and gas reservoir, which lead to high resistivity, but resistivity also changes with fluid content and clay types [4]. Therefore, we can make use of conventional logging to identify shale oil and gas reservoir.

\section{Multivariate Linear Regression Method to Calculate the TOC}

$\Delta \operatorname{lgR}$ technology is widely applied in the TOC logging evaluation [5]. This technology makes the acoustictime and resistivity curves overlap, and the consistent overlap parts in a certain depth range are consided as the baseline, after determining the baseline, the separation of the two curves can be used to identify organic-rich shale, because organic matter and hydrocarbon make the acoustictime and resistivity value become larger. In applications, every two resistivity logarithmic scale corresponding to the acoustictime $-100 \mathrm{us} / \mathrm{ft}$, formula (Eq. 1) is as follows:

$$
\Delta \lg \mathrm{R}=\lg \left(\mathrm{R} / \mathrm{R}_{\text {baseline }}\right)+0.02\left(\Delta \mathrm{t}-\Delta \mathrm{t}_{\text {baseline }}\right) .
$$


In the formula $\Delta \operatorname{lgR}$ is the measured resistivity curve distance in logarithmic coordinates; $\mathrm{R}$ is the measured resistivity, $\Omega \cdot \mathrm{m} ; \Delta \mathrm{t}$ is the measured acoustictime, us/ft. $\mathrm{R}_{\text {baseline }}$ is the baseline corresponding resistivity in non-source rocks; $\Delta \mathrm{t}_{\text {baseline }}$ is the baseline corresponding acoustictime in non-source rocks. TOC has linear correlation with $\Delta \operatorname{lgR}$, and is a function of maturity Ro, $\Delta \operatorname{lgR}$ experience formula (Eq.

2) for computing TOC is:

$$
\mathrm{TOC}=\Delta \lg \mathrm{R} \times 10^{(2.279-0.1688 \times \mathrm{Ro})} .
$$

In the formula TOC is calculated total organic carbon content, \%; Ro is maturity.

Due to the maturity value is difficult to obtain accurately, in order to avoid unnecessary error, here to improve $\Delta \lg R$ method, excluding the uncertainty of maturity. On the basis of multivariate linear regression method, building a multivariate linear relation among TOC, resistivity, acoustictime and density, relation model (Eq. 3) is as follows:

$$
\mathrm{TOC}=\left(\mathrm{x} * \operatorname{lgR}+\mathrm{y}^{*} \Delta \mathrm{t}+\mathrm{z}\right) / \mathrm{DEN} .
$$

$\mathrm{x}, \mathrm{y}, \mathrm{z}$ is to be determined coefficient, DEN is density.

\section{Liaohe Depression Organic-rich Shale Logging Identification}

Liaohe depression is Cenozoic hydrocarbon depression superimposed on the Mesozoic basin. The most active fault depression and fault block activities were at the paleogene chasmic stage, which deposited thick sandstone and mudstone [6]. This model was applied in logging data of Liaohe western depression and eastern depression, and a series of representative logging data was recorded. According to the separation form of the distance between acoustictime (AC) and resistivity (Rt), shale oil and gas effective interval can be divided into three categories: type A. AC and Rt become larger, and the two curves extend; type B. Rt becomes larger, and the curve relative to baseline towards to right, but AC increases not obviously; type $\mathrm{C}$. AC becomes larger, and the curve relative to the baseline towards to left, but Rt increases not obviously. Examples are as follows:

$\mathrm{AC}$ and Rt curves become larger in upper subsection of $3^{\text {rd }}$ member of Shahejie Formation of Shugu 165 Well of western depression, it is a typical of type A curve (Fig. 1). This interval is a large set of mudstone under half deep lacustrine facies with high organic matter content about $3 \%$ average measured TOC. Low density and speed of organic matter make AC becomes larger. Moreover, it has certain organic matter maturity, with Tmax of $430-450^{\circ} \mathrm{C}$. The generated hydrocarbon makes Rt larger. It is a typical of effective shale interval with the lithology logging indicating oil-rich, meanwhile, the tested gas content is $1.52 \mathrm{~m}^{3} / \mathrm{t}$ at $2735 \mathrm{~m}$ proving its effectiveness.

Another effective shale interval is in middle subsection of $3^{\text {rd }}$ member of Shahejie Formation of Shugu165 Well under shallow lacustrine facies (Fig. 2). Rt increases to the right, but AC increases not obviously. It is type B curve. Compared with the former type A shale, the lithology logging indicates oil flecked, and the Tmax significantly become larger, are $450-460^{\circ} \mathrm{C}$. The high maturity induced a mass of hydrocarbon generation, which makes Rt towards to right and becomes larger.

The effective shale interval in upper subsection of $3^{\text {rd }}$ member of Shahejie Formation of Da15 Well of eastern depression is under shore-shallow lacustrine facies (Fig. 3). The sand and shale of this interval are interbeded, and the gas logging of the interval is obvious abnormal. High porosity of sandstone and organic matter of mudstone make AC increases. This curve can be classified as type C. 


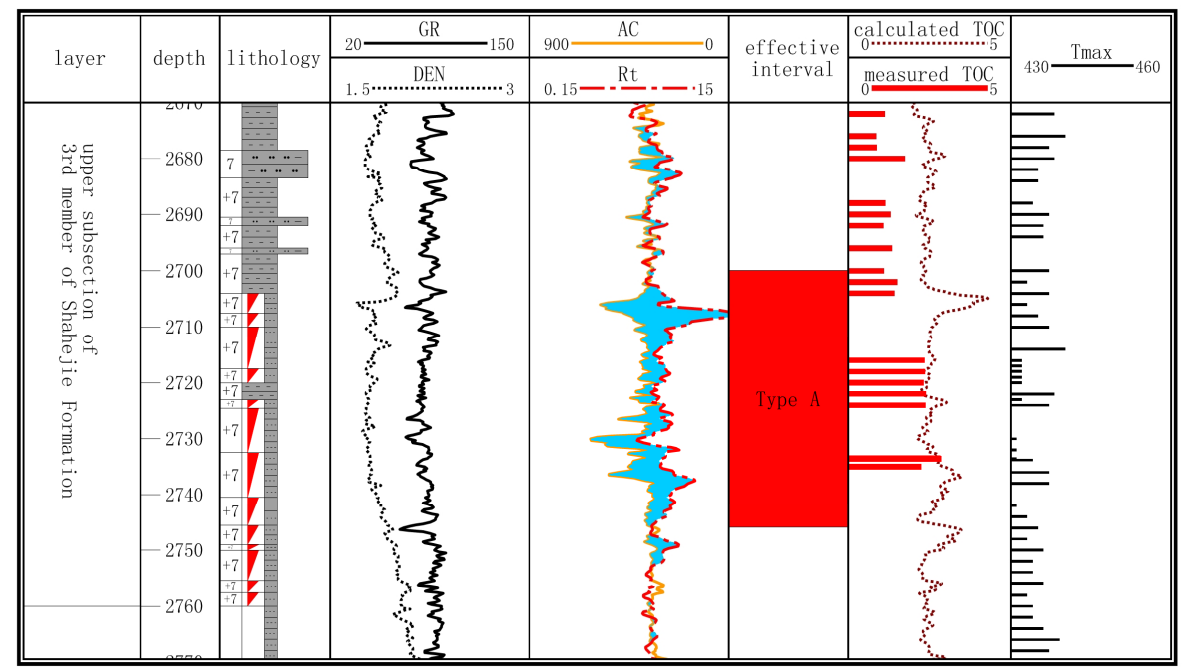

Fig. 1 Type A effective shale interval in upper subsection of $3^{\text {rd }}$ member of Shahejie Formation of Shugu165 Well of western depression

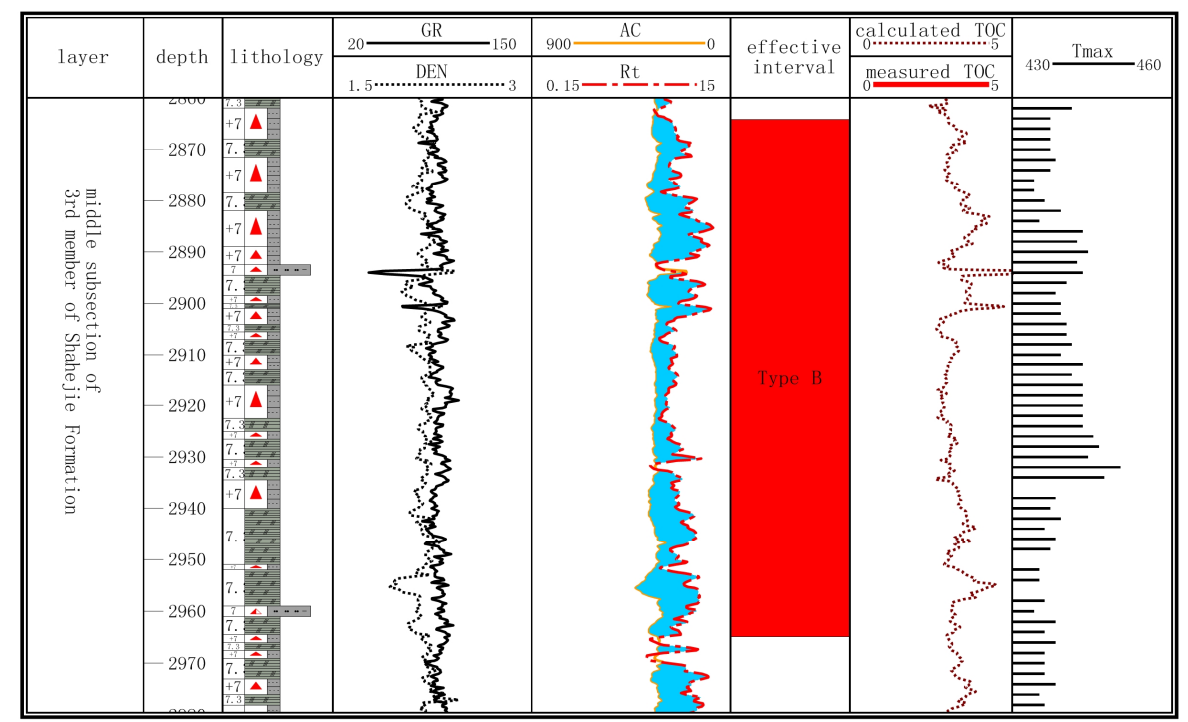

Fig. 2 Type B effective shale interval in middle subsection of $3^{\text {rd }}$ member of Shahejie Formation of Shugu165 Well of western depression

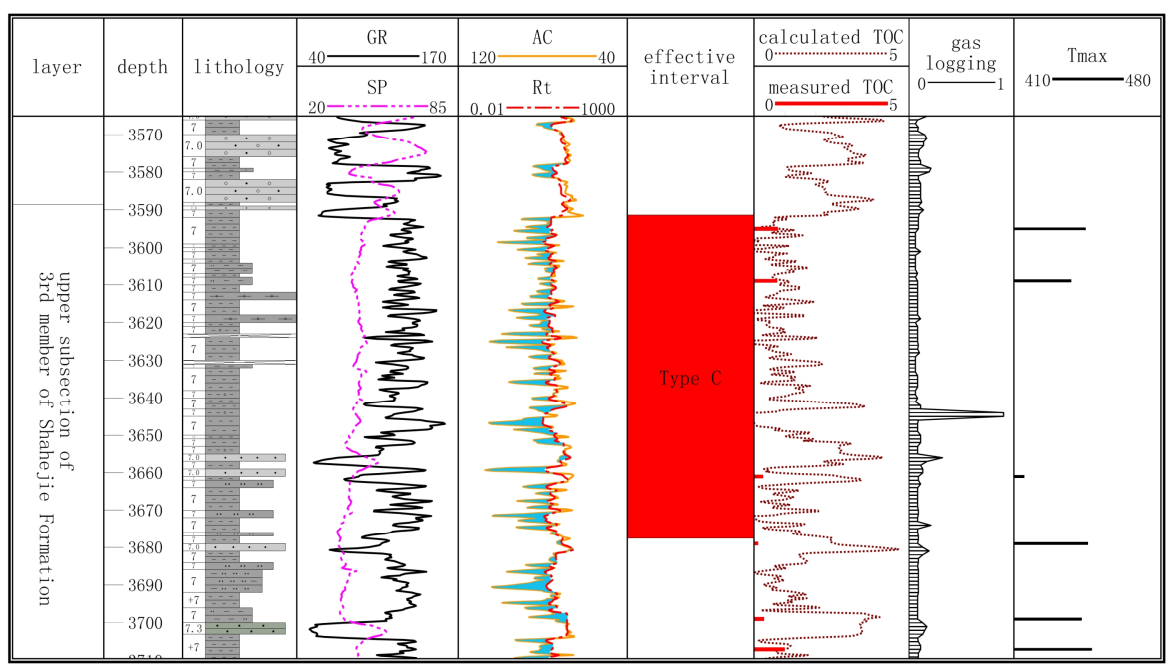

Fig. 3 Type C effective shale interval in upper subsection of $3^{\text {rd }}$ member of Shahejie Formation of Da15 Well of eastern depression 
Based on the results of the statistics, type A, B, C change gradually from deep lacustrine facies to shore-shallow lacustrine facies. Meanwhile TOC and hydrocarbon content also change gradually from high value to low value(Table 1). These phenomenon indicate that high quality shale is generally formed in steady and reducing deep water environment. In this environment, Rich plankton provide plenty of organic matter which is accumulated and conserved in steady and anoxic lake bottom. In addition, deep buried depth makes organic matter has high maturity and mass of hydrocarbon generation. Therefore, these three categories of separate curves form can be used to qualitatively and semi-quantitatively identified the quality level of oil and gas bearing shale.

Table 1 Geological characteristics of three types of curves

\begin{tabular}{cccc}
\hline $\begin{array}{c}\text { Curve } \\
\text { type }\end{array}$ & Sedimentary facies & TOC & $\begin{array}{c}\text { Hydrocarbon } \\
\text { content }\end{array}$ \\
\hline Type A & Deep lacustrine facies & High & High \\
Type B & Semi-deep lacustrine facies & Middle & Middle \\
Type C & Shore-shallow lacustrine facies & Low & Low \\
\hline
\end{tabular}

\section{TOC Logging Calculation Results}

Based on multivariate linear regression formula (Eq. 3), calculated TOC curves are showed with measured TOC in Fig.1-3. Basically, calculated TOC curves have good variation tendency that adapt to measured TOC value, and these TOC curves can be used to fill the blank bewteen measured TOC points effectively. As to the accuracy of the multivariate linear regression formula, taking a crossplot for example(Fig. 4). The crossplot analyze measured TOC and calculated TOC of Shugu165 Well. They has good linear correlation with coefficient $\mathrm{R}^{2}$ of 0.9758 , and the slope of 1.0042 approximately equal to 1 , which indicate multiple linear regression method has small error. Therefore, multivariate linear regression formula is an accurate logging method to calculate TOC, and it has a good practicability in Liaohe depression.

Through multivariate linear regression formula, a series of TOC calculation curves are generated. According to statistics of the TOC calculation curves, the TOC value range of the three types of shale identification curves are calculated. The TOC value of type A curves are $2.3 \%-5 \%$, and average TOC value are $3.5 \%$. The TOC value of type B curves are $1.8 \%-4 \%$, and average TOC value are $2.5 \%$. The TOC value of type $\mathrm{C}$ curves are $0.5 \%-3.3 \%$, and average TOC value are $1.9 \%$.

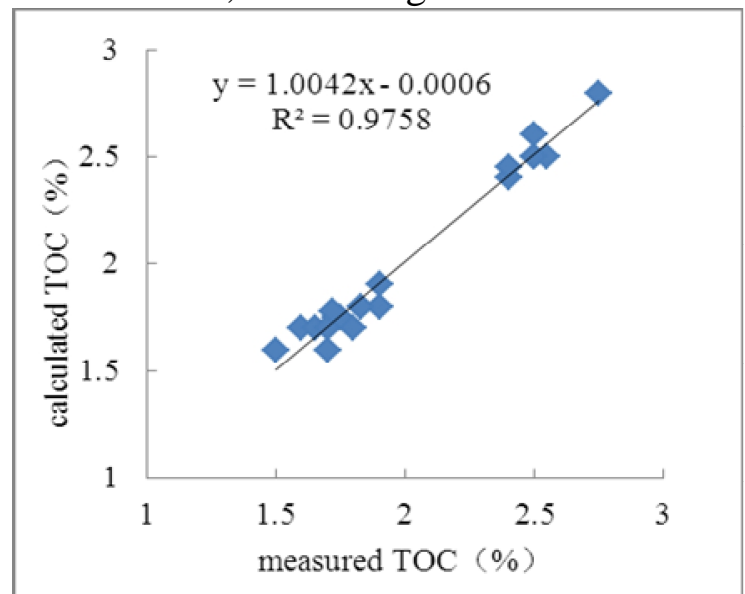

Fig. 4 Crossplot of the calculated TOC and the measured TOC

\section{Conclusion}

Using separation of AC and Rt curves to identify oil and gas bearing shale is an effective logging evaluation means. The separation form can qualitatively and semi-quantitatively determine the quality level of oil and gas bearing shale, and can reflect the sedimentary information as well. TOC fit formula was improved based on $\Delta \lg R$ by multivariate linear regression method which has small error between 
the calculated TOC and the measured TOC. The improved formula has good practicability in Liaohe depression, which can form continuous TOC calculation curves of wells. It is conveniently to use well logging technology to evaluate shale oil and gas.

\section{References}

[1] Jinchuan Zhang .etc: Shale gas reservoir forming mechanism and distribution (2004).

[2] Guiwen Wang, Zhenyu Zhu and Yu Guang: Logging identification and evaluation of Cambrian-Ordovician source rocks in syneclise of Tarim Basin (2002).

[3] Herron S L: A total organic carbon log for source rock evaluation (1987).

[4] Renfang Pan, Yuan Wu and Zheng Song .etc: Geochemical parameters for shale gas exploration and basic methods for well logging analysis (2009).

[5] Passey Q R: A practical model for organic richness from porosity and resistivity logs (1990).

[6] Hongbin Sun and Fenglian Zhang: Structural-sedimentary evolution characteristics of Paleogene in Liaohe Depression (2008). 